\title{
Climate Skepticism and the Manufacture of Doubt: Can Dissent in Science be Epistemically Detrimental?
}

\author{
Justin B. Biddle, Ph.D. (corresponding author) \\ Philosophy Program \\ School of Public Policy \\ Georgia Institute of Technology \\ Email: justin.biddle@pubpolicy.gatech.edu
}

Anna Leuschner, Ph.D.

Karlsruher Institut für Technologie

Institut für Philosophie

Email: anna.leuschner@kit.edu

\begin{abstract}
The aim of this paper is to address the neglected but important problem of differentiating between epistemically beneficial and epistemically detrimental dissent. By "dissent," we refer to the act of objecting to a particular conclusion, especially one that is widely held. While dissent in science can clearly be beneficial, there might be some instances of dissent that not only fail to contribute to scientific progress, but actually impede it. Potential examples of this include the tobacco industry's funding of studies that questioned the link between smoking and lung cancer, and the attempt by the petroleum industry and other groups to cast doubt upon the conclusion that human consumption of fossil fuels contributes to global climate change. The problem of distinguishing between good and bad dissent is important because of the growing tendency of some stakeholders to attempt to delay political action by 'manufacturing doubt' (Oreskes \& Conway 2010). Our discussion in this paper focuses on climate science. This field, in our view, is rife with instances of bad dissent. On the basis of our discussion of climate science, we articulate a set of sufficient conditions for epistemically problematic dissent in general, which we call "the inductive risk account of epistemically detrimental dissent."
\end{abstract}

Acknowledgments. Each author is responsible for the paper in its entirety, and both authors contributed equally to the final product. Earlier drafts of this paper were presented at Bielefeld University, Tilburg University, Georgia Institute of Technology, and the GAP.8 conference at the University of Konstanz. We would particularly like to thank Paul Baer, Gregor Betz, Sebastian Cacean, Martin Carrier, Matt Cox, Michael Hoffmann, Paul Hoyningen-Huene, Philip Kitcher, Frederike Neuber, Bryan Norton, Naomi Oreskes, Juha Saatsi, Christian Voigt, John Walsh, Torsten Wilholt, and Eric Winsberg for their valuable comments. Thanks also to the Notre Dame Institute for Advanced Study for support. 


\section{Introduction}

The aim of this paper is to address the neglected but important problem of differentiating between epistemically beneficial and epistemically detrimental dissent in science. By 'dissent,' we refer to the act of objecting to a particular conclusion, especially a conclusion that is widely held. We use the terms 'beneficial' and 'detrimental' primarily in an epistemic sense, such that beneficial dissent is dissent that contributes to knowledge production, and detrimental dissent is dissent that impedes knowledge production. Though the primary focus of this paper is epistemic, we will end up arguing that the problem of distinguishing between epistemically beneficial and epistemically detrimental dissent has an ineliminable ethical dimension.

Virtually all philosophers of science regard dissent as beneficial. Some, such as Popper, regard it as unequivocally beneficial. On his view, the sole epistemological task of the scientist is to attempt to falsify hypotheses; not only does consensus play no positive epistemological role, but it is viewed with suspicion, like a political ideology that is forbidden to be questioned. Most other, less extreme, theories of science also recognize a positive role for consensus, but all of these regard dissent as epistemically beneficial. They stress that without critical exchange, the process of examining, reworking, refining, and improving scientific hypotheses would be difficult, if not impossible.

While there is no question that dissent in science can be (and typically is) epistemically beneficial, we believe that there are some instances of dissent that not only fail to contribute to scientific progress, but actually impede it. These cases are becoming increasingly common in policy-relevant research, because there is a growing tendency of some stakeholders to attempt to delay political action by 'manufacturing doubt' (Oreskes and Conway 2010). Potential examples of this include the tobacco industry's funding of studies that questioned the link between smoking and lung cancer, and the attempt by the petroleum industry and other groups to cast doubt upon the conclusion that human consumption of fossil fuels contributes to global climate change (e.g., Oreskes and Conway 2010; Kitcher 2011; Proctor and Schiebinger 2008). Manufacturing doubt not only tends to delay political action that could benefit society; it can also inhibit scientific progress. In particular, we will argue that, under certain conditions, dissent can retard progress by (1) forcing scientists to respond to a seemingly endless wave of unnecessary and unhelpful objections and demands and (2) creating an atmosphere in 
which scientists fear to address certain topics and/or to defend hypotheses as forcefully as they believe is appropriate. Our discussion in this paper will focus on climate science. This field, in our view, is rife with instances of epistemically detrimental dissent. One potential example of this is the American Enterprise Institute's (AEI) offer of $\$ 10,000$ (USD) to scientists who provide results that contradict the fourth assessment report of the Intergovernmental Panel on Climate Change (IPCC) (AEI 2007; Mann 2012, p. 67). Intuitively, one might think that there is something wrong with this offer, that it is an attempt to 'buy' particular research outcomes that serve particular political and economic goals. We agree that there is something wrong with the offer, though it turns out that explicating precisely what is wrong with it is more difficult than it might first appear.

The primary aim of this paper is to identify what is wrong with much of the dissent that is put forward by climate skeptics 1 and, on the basis of this, to spell out a set of jointly sufficient conditions for epistemically problematic dissent in general. We do not attempt to specify necessary conditions of epistemically detrimental dissent; this aim, if it is indeed achievable, is well beyond the scope of this paper. We begin, in Section 2, by addressing the narrow issue of what is wrong with the AEI offer. We discuss a couple of candidate reasons why one might intuitively think that the offer is problematic, and we argue that they are inadequate. The inadequacy of these candidate reasons motivates an extended discussion of epistemically detrimental dissent in climate science. In Section 3, we show how studies from climate skeptics have been used as a basis of attacks on climate scientists Michael Mann, Raymond Bradley, and Malcolm Hughes. In Section 4, we argue that the attacks on Mann, Bradley, and Hughes are by no means a special or isolated case, and we provide evidence for the epistemic influence of climate skepticism on climate science. In Section 5, we motivate our proposal with a discussion of inductive risk and conventional standards, and in Section 6, we introduce and defend the inductive risk account of epistemically detrimental dissent (or simply, the inductive risk account). While the conditions that we articulate in the inductive risk account are based upon our discussion of climate science, we will provide some reasons to believe that they can also identify other instances of detrimental dissent, particularly in policyrelevant research. In this way, our account is not only theoretically significant but also

1 By referring to "climate skeptics" we do not mean "skeptical climate scientists" who merely "hold a skeptical view of the validity and utility of [climate ...] models"; in Myanna Lahsen's and Riley E. Dunlap's terminology we are discussing the case of "dissident" or "contrarian scientists" who "strongly criticize climate science and in many cases participate in the denial machine" (Dunlap 2013, p. 693; cf. also Lahsen 2008). 
addresses the practical problem of identifying real-world cases of epistemically problematic dissent.

\section{On what is not wrong with the AEI offer}

One might find the AEI offer to be epistemically problematic because it does not reward just any research that meets high epistemic standards; rather, it rewards only research that obtains a specific set of results. On this account, dissent is epistemically problematic when it comes from individuals or groups that are not open to just any result, but rather are interested in obtaining only a specific result. This view is open to serious objections.

According to many accounts of scientific progress, it is normal and even epistemically beneficial for scientists to attempt to obtain specific results (e.g., Kuhn 1962; Lakatos 1970). In Kuhnian terms, paradigms provide scientists with fairly clear ideas of how many experiments will turn out. Scientists working within a paradigm will consequently attempt to achieve these particular results; moreover, if they should fail, they will question their own investigations or aptitudes before they question the reigning paradigm. The guidance provided by a paradigm is, according to Kuhn, epistemically beneficial, as it helps to structure scientists' investigations and outline what counts as acceptable and unacceptable results. Lakatos's methodology of scientific research programmes is similar in this regard; it includes rules such as a negative heuristic (research paths to avoid) and a positive heuristic (research paths to pursue), which help to save scientists "from becoming confused by the ocean of anomalies" (Lakatos 1970, p. 193). On both of these accounts, not only is there nothing necessarily problematic about scientists attempting to obtain a specific set of results; it is often epistemically beneficial to do so. While there are many unresolved issues in climate science, there is an established theoretical and instrumental framework in place that helps to structure future research problems and the space of likely solutions to these problems. That there is broad agreement concerning the outlines of such a framework is evidenced by the IPCC reports, among other studies (e.g., Oreskes 2004). Given this, it is not necessarily problematic to attempt to achieve a specific set of results.

Another potential reason for thinking that there is something epistemically problematic with the AEI offer is that it appears to be motivated by a political and economic agenda. Clearly, there are powerful industries that have an economic stake in stalling political action to regulate greenhouse-gas emissions, and there are influential 
think tanks (such as the $\mathrm{AEI}$ ) that promote an anti-regulatory agenda. One might argue that dissent is epistemically problematic when it is put forward by groups that have an economic stake - or some other significant non-epistemic stake - in the result. However, as Kitcher has argued, there are many situations in which 'impure' motivations - such as the desire for credit, fame, or financial reward - can be put to good epistemic use (Kitcher 1993). More specifically, there are situations in which communities of 'epistemically sullied agents' (which he defines as agents who strive to achieve both a non-epistemic goal such as credit and an epistemic goal such as truth) perform better at an epistemic task than communities of 'epistemically pure' agents. The reason for this is that impure motivations, such as the desire for credit for achieving a particular result first, can help to distribute the labor of individual scientists over a multiplicity of different research strategies, which is epistemically beneficial for the community as a whole. Given this, the mere fact that the AEI offer is motivated at least in part by political and/or economic interests does not imply that the offer is epistemically detrimental.

A somewhat better (but still inadequate) account of why the AEI offer might be problematic can be seen by examining Kitcher's discussion further. Suppose that the $\mathrm{AEI}$ is motivated solely, not just in part, by political or economic interests, and that those who agree to accept the AEI offer are motivated solely by such considerations. As Kitcher makes clear, 'grubby' motives can only promote scientific progress when they are combined with the motive to seek epistemic goals such as truth or reliability. Absent the goal of truth or reliability, there is little to prevent research - including the choices of hypotheses to consider, the adoption of methods for the evaluation of results, and the characterization or interpretation of data - from being skewed to achieve desired results. In cases in which motivations are not merely sullied, but depraved, we might consider dissent to be epistemically detrimental.

We think that it is plausible that, if climate skeptics are motivated solely by political or economic considerations, then their dissent is epistemically detrimental (call this the depraved motivations account of epistemically detrimental dissent (or simply, the depraved motivations account)). There are, however, problems with this account. First, while it might be true that some climate skeptics have depraved motivations, there might be others who genuinely believe either that human activity is not contributing to global climate change or that we have no good reason for believing that this is so. Some recent work in social psychology suggests that climate skepticism cannot be explained solely in terms of political or economic interests, and that 'conspiracist ideation,' or a tendency to 
endorse conspiracy theories, also plays an explanatory role (e.g., Lewandowsky, Gignac, and Oberauer 2013). While these findings do not, strictly speaking, constitute an objection to the depraved motivations account as a sufficient condition for epistemically detrimental dissent, they suggest that the usefulness of the account might be very limited. If we want an account of epistemically detrimental dissent that also applies to epistemically-motivated climate skepticism, then we need an account that is more general than the depraved motivations account.

Second, if the only way to determine whether dissent is problematic is to accurately identify the intentions of those putting forward the dissent, then it will be difficult to determine, in any given case, whether dissent is problematic. Scientists are motivated by all sorts of factors, and it is extremely difficult, in any given case, to argue convincingly that a scientist or group of scientists is motivated solely or even predominantly by non-epistemic aims. This objection does not assert that the depraved motivations account is false (or even too narrow); as such, it does not purport to identify a theoretical problem with the account. It does, however, identify a practical problem with employing this account to pick out real-world cases of epistemically detrimental dissent.

In Sections 5-6, we will attempt to provide a better account of epistemically detrimental dissent. Before doing this, however, it will be helpful to discuss some actual examples of climate skepticism and the uses to which they have been put.

\section{The attacks on Mann, Bradley, and Hughes}

Since at least the mid-1990s, there has been a consensus that most of the Earth's warming over the past half a century is likely due to increases in greenhouse gas emissions. In 1988, James Hansen testified to the U.S. Congress that the Earth is warming and that greenhouse gas emissions are very likely one of the causes (Oreskes and Conway 2010, p. 184). In 1995, the IPCC Second Assessment Report concluded that "the balance of evidence suggests that there is a discernable human influence on climate" (IPCC 1995, p. 22), and since that time, the debate within the field of climate science over whether greenhouse gas emissions are contributing to global climate change has largely been settled (e.g., Oreskes 2004). The most recent IPCC report states: "Human influence on the climate system is clear. This is evident from the increasing greenhouse gas concentrations in the atmosphere, positive radiative forcing, observed warming, and understanding of the climate system" (IPCC 2013, p. 15). 
Despite this, climate skeptics (most of whom are not climate scientists) continue to argue either that there is no anthropogenic global climate change - i.e., that climate change, if it is happening at all, is exclusively due to natural causes - or that the anthropogenic factors are negligible as compared to natural causes (Elsasser and Dunlap 2013, pp. 764-766). Based on this skepticism, climate scientists have become targets of professional and personal attacks. In this section, we will focus our attention on the case of Mann, Bradley, and Hughes.

Probably the most famous figure in climate science is the 'hockey stick graph,' which represents changes in the Earth's temperature from over several centuries, and which depicts in easy-to-understand form the dramatic rise in northern hemisphere temperatures since the mid-twentieth century. The original publication - a 1998 article in Nature by Mann, Bradley, and Hughes (or MBH98) - graphed temperatures back to 1400 A.D.; in a subsequent publication, they graphed temperatures back to 1000 A.D. (Mann, Bradley, and Hughes 1999, or MBH99). Immediately after the publication of MBH98, the hockey stick became the subject of a media blitz (Mann 2012, p. 49), and it helped to bring the notion of anthropogenic climate change into mainstream culture. It was also featured prominently in the IPCC Third Assessment Report from 2001.2

Because of the dramatic way in which it represented late-twentieth-century warming, the graph quickly became the target of attacks from climate change deniers. Stephen Mclntyre and Ross McKitrick (neither of whom are climate scientists) published a paper in which they claimed to invalidate the hockey stick graph on the grounds that it was supported by bad data (Mclntyre and McKitrick 2003). They reached this conclusion by using an incorrect version of the proxy data set used in MBH98 (Rutherford et al. 2005 , p. 2312). In a subsequent article, they argued that the hockey stick is an artifact of the statistical conventions chosen in MBH98 (Mclntyre and McKitrick 2005). Their argument in this paper targeted MBH's use of principle component analysis (PCA), which is a statistical procedure that can be used to represent large data sets in terms of a smaller number of patterns. $\mathrm{MBH}$ used this procedure to deal with the problem of diverse proxy data, which included large sets of tree ring data and smaller sets of data from other sources (MBH98; Mann 2012). Mclntyre and McKitrick (2005) argued that the hockey stick pattern is an artifact of the choice of a convention for centering tree ring data; more specifically, they argued that if one centers tree ring data at the twentieth

2 http://www.grida.no/publications/other/ipcc tar/?src=/climate/ipcc tar/wg1/005.htm. Accessed 19 April 2014. 
century, the hockey stick pattern appears, but that if one centers it around a long term average (from 1400-1980), then the pattern does not appear. Like their previous argument that the hockey stick pattern is an artifact of bad data, this more recent argument was deeply flawed and quickly exposed as such. $\mathrm{MBH}$ analyzed the data into two principle components (PCs), one that describes periodic, oscillating temperature changes, and the other that describes global warming. Mclntyre and McKitrick adopted a retention criterion for PCs that had the effect of tossing out the global warming PC; "they had chosen to throw out a critical pattern in the data as if it were noise, when an objective analysis unambiguously identified it as a significant pattern" (Mann 2012, p. 138). This problem is confirmed in Wahl and Ammann (2007).

Despite the fact that Mclntyre and McKitrick's dissenting research was deeply problematic - it violates the standard of ensuring that the data that one tosses out is, in fact, noise and not signal - and easily dismissed by competent climate scientists, it was (and still is) used by the authors, some scientists, politicians, conservative think tanks, and others to advance their ends (see below). Perhaps unsurprisingly, some politicians use it to attempt to stall climate change legislation. For example, U.S. Senator James Inhofe, a notorious climate change denier, used Mclntyre and McKitrick's first paper to oppose the 2003 U.S. Climate Stewardship Act, which would have established a cap and trade system, among other things (Mann 2012, p. 122). Moreover, this dissenting research has also been used to attack prominent climate scientists and climate science as a field.

Though climate scientists quickly dismissed the objections of Mclntyre and McKitrick, the conservative popular media did not. In particular, Antonio Regalado published a piece in the Wall Street Journal that treated Mclntyre like a modern-day Galileo - a fearless outsider who exposed the weaknesses of an established consensus (Regalado 2005). Regalado's article received a lot of attention, including from Joe Barton, a conservative Congressman, head of the House Energy and Commerce Committee, and staunch supporter of the fossil fuel industry (Mann 2012, p. 149). In June 2005, Barton sent letters to Mann and to a number of other scientists, including Bradley, Hughes, Rajendra Pachauri (chair of the IPCC), and Arden Bement (director of the U.S. National Science Foundation). The letter to Mann began by citing Regalado's article, which raised questions "about the significance of methodological flaws and data errors" in the MBH papers (quoted in Mann 2012, p. 151). Barton proceeded to demand that Mann hand over extensive materials to him, including lists of funding sources, 
locations of data archives, supporting documentation such as computer source code, timelines of when information was available to whom, and extensive descriptions of Mann's research history and progress. Furthermore, Barton instructed Mann to:

Explain in detail your work for and on behalf of the Intergovernmental Panel on Climate [sic] ... including the process for review of studies and other information, including the dates of key meetings ... the steps taken by you, reviewers, and lead authors to ensure the data underlying the studies forming the basis for key findings of the report were sound and accurate ... the requests you received for revisions to your written contribution ... and ... the identity of the people who wrote and reviewed ... portions of the report. (Quoted in Mann 2012, p. 152) Barton suggested in the letter that he had the authority to compel Mann to provide this information, though he did not in fact have this authority. Nonetheless, Mann understandably felt threatened by the letters and believed that he needed to respond. $\mathrm{He}$ wrote:

Barton's letters appeared intended to send shivers down our spines, and certainly did succeed to an extent. Moreover, he sidelined us with vexatious demands, the response to which both proved a major time sink and required us to solicit legal advice and representation. Needless to say, I would have rather been spending my time meeting my teaching, advising, and professional obligations and advancing various scientific research projects. Responding to such intimidation tactics was most certainly not what I had bargained for when I chose to go into science. (Mann 2012, p. 151)

Happily, many prominent climate scientists and scientific organizations responded publicly to Barton's letters, expressing their support for Mann and his colleagues and their concern over Barton's blatant attempt to intimidate scientists. By this time, however, the hockey stick graph had become the subject of intense political debate, which would lead U.S. Congressmen to commission two reports on the $\mathrm{MBH}$ studies.

The first report, commissioned by Representative Sherwood Boehlert, was by the prestigious U.S. National Academy of Sciences (NAS); it was carried out by a diverse array of experts in climate science, and it went through a rigorous peer review process. The NAS report vindicated the work of $\mathrm{MBH}$, concluding that there is "high confidence" that the planet is the warmest in the past 400 years and "less confidence" in temperature 
reconstructions prior to 1600.3 This is consistent with the uncertainties acknowledged in the $\mathrm{MBH}$ studies. The second report, commissioned by Barton, was by Edward Wegman (a statistician) and two associates (one of whom was his graduate student). None is an expert in climate science. The Wegman report repeated uncritically the conclusions of McIntyre and McKitrick, and it produced a network analysis that purported to show that the community of climate scientists is highly insular, such that its members do not interact with scientists outside their group. The report was published in a peer-reviewed journal but later retracted on the grounds of plagiarism. 4

A little over a year after sending letters to Mann and others, Barton called Congressional hearings entitled "Questions Surrounding the 'Hockey Stick' Temperature Studies: Implications for Climate Change Assessments." He called the hearings on the basis of the findings of the Wegman report (which was, again, based in part on the McIntyre and McKitrick papers). Wegman and Mclntyre were both witnesses, as were a number of established climate scientists who defended the MBH studies. There is little doubt which side won the arguments of these hearings; the criticisms of Barton, Wegman, and the others who continued to question the hockey stick graph were shown (once again) to be baseless. But the hearings also showed that prominent climate scientists whose research is perceived to undermine business-as-usual practices might pay a high price - not only in terms of time and resources, but also in threats to their physical and emotional well being (e.g., Mann 2012, pp. 226-228). This would be put on display again a few years later in the so-called "climategate" scandal, which we will discuss in the following section.

\section{Climate skepticism and its effects on climate science}

The attacks on Mann, Bradley, and Hughes were extreme, in large part because of the popularity garnered by the hockey stick graph; most climate scientists do not experience attacks of this intensity. But it would be a mistake to think that the $\mathrm{MBH}$ case is an isolated incident; many other prominent climate scientists are subjected to extreme attacks. Ben Santer, a scientist in the Program for Climate Model Diagnosis and Intercomparison at the U.S. Lawrence Livermore National Laboratory, was the subject of intense attacks after serving as lead author for chapter 8 of the second IPCC report.

3 http://www8.nationalacademies.org/onpinews/newsitem.aspx?RecordID=11676. Accessed 19 April 2014.

4 http://sciencedirect.com/science/article/pii/S0167947307002861\#. Accessed 19 April 2014. 
Some of these attacks were based on dissenting studies from the contrarian Patrick Michaels and then disseminated by conservative think tanks and newspapers (such as the George C. Marshall Institute and the Wall Street Journal, respectively) (Oreskes and Conway 2010, pp. 197-213). Others were based on the dissenting studies of John Christy and Roy Spencer (Lloyd 2012). Additionally, Santer has been harassed by Mclntyre, who has used the U.S. Freedom of Information Act (FOIA) to demand information about his research (Oreskes and Conway 2010, p. 264). James Hansen and Stephen Schneider have been the subject of similar attacks (Bowen 2008; Schneider 2009).

These attacks on prominent climate scientists indicate two ways in which certain forms of dissent in climate science can be epistemically problematic. They can inhibit scientific progress by (1) forcing scientists to respond to a seemingly endless wave of unnecessary and unhelpful objections and demands and (2) creating an atmosphere in which scientists fear to address certain topics and/or to defend hypotheses as forcefully as they believe is appropriate. We will examine both of these effects in more detail here.

First, these attacks waste resources. Scientists should of course respond to serious objections to their work, but Mann, Bradley, Hughes, Santer, Hansen, Schneider, and others have been forced to respond over and over again to objections that have already been answered - and many have been forced to do so not just in print, but in front of the U.S. Congress. They have had to do this in part because of the political authority that the objections have acquired. In some cases, it is reasonable to ignore baseless objections put forward for political purposes. But when those objections are disseminated by powerful conservative think tanks, when they are promulgated in prominent publications such as the Wall Street Journal, and when they are used by politicians in attempts to stall important climate legislation, climate scientists ought to respond. They should respond because they have a moral obligation to society and also to defend their reputations. This requires a lot of time and energy that could have been spent advancing their research programs. In this way, some dissent in climate science slows scientific progress.

Secondly, it is plausible to think that these attacks have an even more insidious effect on research - that they affect the broader field of climate science, not just those scientists who are the immediate objects of attack - by creating an atmosphere in which researchers fear to investigate particular hypotheses or draw strong conclusions in support of those hypotheses. In an open letter in the journal Science, 250 scientists 
protested against the "McCarthy like threats of criminal prosecution against our colleagues based on innuendo and guilt by association, the harassment of scientists by politicians seeking distraction to avoid taking actions, and the outright lies being spread about them" (Sills 2010, p. 689). In some cases, climate scientists have been subjected to threats to personal well being and even death threats, both publicly by conservative politicians in the media and privately via anonymous emails from incited people (e.g., Mann 2012, pp. 224-227).5 It is plausible to worry that these attacks will influence the types of problems that other scientists will be likely to address and/or the conclusions that they are willing to defend. Moreover, there is empirical evidence that substantiates this worry.

A number of recent studies have concluded that IPCC reports consistently err on the side of underestimating causes and impacts of climate change. For example, a number of empirical studies have confirmed that IPCC reports have consistently underestimated $\mathrm{CO}_{2}$ emissions and sea level rise (Freudenburg and Muselli 2010; NRC 2009; Rahmstorf et al. 2007; UNEP 2009). There are a number of potential explanations of this trend. For example, Brysse et al. (2013) argue that a part of the explanation is the tendency of scientists to "err on the side of least drama," which flows from the traditional emphasis upon avoiding false positives over false negatives. But they also argue that it might not be the full explanation, especially in countries such as the U.S., where climate denialism has strong political and economic support:

The frequent attacks on Stephen Schneider - as well as attacks on other climate scientists such as Benjamin Santer and Michael Mann - suggest that one possible reason why scientists may have underestimated the threat of anthropogenic warming is the fear that if they don't, they will be accused by contrarians (as was Schneider) of being alarmist fear-mongers. That is to say, pressure from skeptics and contrarians and the risk of being accused of alarmism may have caused scientists to understate their results. (Brysse et al. 2013, p. 330)

While this possibility is difficult to establish definitively, climate scientists have stated that denialist attacks have, in fact, had this effect. For example, Oreskes and Conway write:

At a recent conference, a colleague told one of us that in IPCC discussions,

5 There is no evidence, as far as we are aware, that the dissenting scientists are directly responsible for threats to personal well being or death threats. However, the dissent - and particularly the ways in which that dissent is used by some politicians and media outlets - helps to create the conditions for such threats. 
some scientists have been reluctant to make strong claims about the scientific evidence, lest contrarians 'attack us'. Another said that she'd rather err on the side of conservatism in her estimates, because then she feels more 'secure.' (Oreskes and Conway 2010, pp. 264-265)

Whether denialist attacks have been effective in leading climate scientists to alter the hypotheses they investigate and/or the strength of their conclusions requires further investigation; but as we have shown, there are empirical grounds for worrying that they have.

In the next section, we will provide a general account of epistemically detrimental dissent, one that applies beyond climate science. Before we do this, however, it is worth elaborating on the precise role that dissenting research plays in attacks against mainstream climate scientists. After all, attacks against climate scientists need not rely upon dissenting research at all. The "climategate" scandal - in which someone hacked into a server at the University of East Anglia's Climate Research Unit (CRU), stole and published emails from a number of climate scientists (including Santer, Mann, Kevin Trenberth, Tom Wigley, Keith Briffa, and Phil Jones), and then publicized parts of those emails taken out of context - involved attacks on climate scientists, but the attacks were not based on research at all (Mann 2012, pp. 207-232).

What is the point of focusing on specific forms of dissenting research? We focus on these forms of dissenting research because the strategic use of such dissent as another weapon in the arsenal of those who would attempt to undermine scientific authority in order to postpone political regulation measures is a growing problem. Skeptics and deniers often attempt to justify their dissent by arguing that it plays an important role in scientific progress. For example, Christopher DeMuth, director of the aforementioned American Enterprise Institute (AEI), stresses that "consensus plays an important role in science and scientific progress, but so does disputation - reasoned argument is essential to good science, and competition of ideas is essential to scientific progress" (AEI 2007, att.3, 2). However, as we seek to demonstrate, there can well be dissent that is not epistemically fruitful at all, but that retards scientific progress. Such dissent is not justified by scientific reasons but is rather detrimental to both science and society.

\section{Inductive risk and the evaluation of dissent}


In this section, we will propose a set of jointly sufficient conditions for epistemically detrimental dissent in general. This account draws upon the notion of inductive risk, or the risk of wrongly accepting or rejecting a hypothesis; before presenting our account of epistemically detrimental dissent, it will be helpful to discuss inductive risk and its implications.

A number of philosophers have drawn upon inductive risk in order to argue that value judgments - even ethical value judgments - play an ineliminable role in the evaluation of scientific hypotheses (Douglas 2000; Elliott 2011; Wilholt 2009). The most well-known version is due to Richard Rudner, who argues that the scientist qua scientist accepts or rejects hypotheses, and that no hypothesis can ever be completely (with $100 \%$ certainty) verified. The decision to accept or reject a hypothesis depends upon whether the evidence is sufficiently strong, and whether the evidence is sufficiently strong is "a function of the importance, in a typically ethical sense, of making a mistake in accepting or rejecting the hypothesis" (Rudner 1953, p. 2, emphasis in original). Therefore, the scientist qua scientist makes (ethical) value judgments. To paraphrase Rudner's well-known example, if the hypothesis in question is that a drug does not have serious side effects, we should require a high degree of confirmation before accepting the hypothesis, whereas if the hypothesis is that a lot of belt buckles is not defective, we need not require such confidence. "How sure we need to be before we accept a hypothesis will depend upon how serious a mistake would be" (Rudner 1953, p. 2). While some have attempted to show that the argument from inductive risk is not successful in establishing that values play an ineliminable role in the epistemic evaluation of hypotheses, we think that these objections fail. 6 Thus, for the remainder of this paper, we will assume that the argument from inductive risk successfully establishes that values ineliminably influence the epistemic evaluation of hypotheses.

Yet, if the argument from inductive risk is successful, we must answer the question of how we can distinguish between cases of acceptable value-influence and cases of illegitimate bias. To do this, consider the example of research on the health effects of bisphenol A, as discussed by Wilholt (2009). While many studies have drawn an association between bisphenol $A$ and adverse health effects, most industry-funded studies have found no such correlation. In fact, $90 \%$ of government-funded studies investigating the effects of low-dose exposure to bisphenol A found a correlation, while

6 The two most well-known sets of objections are those of Jeffrey (1956) and Levi (1960). For responses to Jeffrey (1956), see Biddle and Winsberg (2010) and Biddle (2013). For responses to Levi, see Wilholt (2009). 
none of the industry-funded studies did so (vom Saal and Hughes 2005; Wilholt 2009).

Further investigation into some of these industry-funded studies shows that they used as model organisms a strain of rat that was particularly insensitive to estrogen. Given that the toxicity of bisphenol $A$ is associated with its similarity to human estrogen, this choice of a model organism significantly lowered the probability of finding an association with adverse health effects. Hence, the choice can be viewed through the lens of the argument from inductive risk, as it lowered the risk of obtaining false positives at the expense of a significantly higher risk of false negatives. (In other terminology, it lowered producer risks at the expense of consumer risks, or what we prefer to call "public risks".7) Now, could one draw upon Rudner's argument in order to show that these industry-funded studies were value-laden, as opposed to biased? After all, in every experiment, we must make decisions that involve a trade-off between risk of false positives and false negatives; industry might do this one way, other stakeholders another, but because each of these decisions is value-based, one might argue that we cannot accuse one of bias and the other not.

Wilholt (2009) argues that, despite the fact that all hypothesis-appraisal is inevitably value-laden, we can still show that the industry studies on bisphenol $A$ are not merely value-laden but biased by appealing to conventional standards. There are many decisions in science that are not dictated by either logic or evidence, but that require judgment calls on the part of individuals. The determination of what counts as a statistically-significant result is one such decision, but there are many others. 8 The use of a strain of rat that is particularly insensitive to estrogen violates a conventional standard in toxicology that was made explicit by a group of experts convened by the U.S. National Toxicology Program: "Because of clear species and strain differences in sensitivity, animal model selection should be based on responsiveness to endocrine active agents of concern (i.e., responsive to positive controls), not on convenience and

7 The terminology of 'producer risks' and 'public risks' is a variant on that of 'producer' and 'consumer' risks. Producer risks are risks of wrongly accepting hypotheses, when doing so would primarily harm producers; consumer risks are risks of wrongly rejecting hypotheses, when doing so would primarily harm consumers. The phrases 'producer' and 'consumer risks' are typically used in the context of technology assessment and policy-relevant science. We use the phrase 'public risks' instead of 'consumer risks,' because there are consequences that fall primarily on the public, even if they do not result from consuming any particular product.

8 Particularly Kuhn $(1977$, p. 332) pointed out that the choice of methodological standards in science is influenced by contextual, non-epistemic preferences of scientists. Note that this does not mean that these standards are arbitrary. It merely means that the choice of methodological standards is empirically underdetermined and hence influenced to some degree by non-epistemic values. Longino (e.g., 2002, pp. 130-131) also stresses that criticism in science can only be fruitful when it fulfills conventional ("public") standards. 
familiarity" (quoted in Wilholt 2009, p. 97). Of course, choosing species and strains in this way is perfectly reasonable - it might, in fact, seem completely obvious - but it is a matter of convention. The industry studies on bisphenol A did not just choose a strain that would raise the probability of obtaining a desired result; in so doing, they also violated a well-entrenched conventional standard. It is this violation that sets the research apart as being biased, rather than just value-laden.

The research by McIntyre and McKitrick (discussed in Section 3), which was used as a basis of attacks against Mann, Bradley, and Hughes, is also biased in the above sense. It involves value-laden decisions that raise the probability of obtaining a particular result (namely, that there has been no significant increase in northern hemisphere temperatures), and these decisions involve violations of conventional standards (e.g., the very basic standard of ensuring that the data that one tosses out is noise and not signal).

In many cases in which there are significant non-epistemic consequences of being wrong, producer risks and public risks tend to fall on different parties. The consequences of wrongly accepting the hypothesis that bisphenol $A$ has deleterious health effects fall primarily on industries that produce this chemical; the consequences of wrongly rejecting the hypothesis fall primarily on the public, especially those exposed to the chemical. Something similar can be said of the hypothesis of anthropogenic climate change $\left(H_{a c c}\right)$; the consequences of wrongly accepting $H_{a c c}$ fall primarily upon specific industries that are responsible for deforestation and greenhouse gas emissions, while the consequences of wrongly rejecting $H_{a c c}$ fall primarily on the public, especially on current populations in developing countries and on future generations due to sea level rise, floods, and droughts. The case of climate change is, of course, complicated.9 The public, especially in affluent countries, benefits from industrially produced products. Because of this, the consequences of wrongly accepting $H_{a c c}$ would impact many parties throughout the world. But it would impact some much more than others. Industries that rely upon significant greenhouse gas emissions in order to achieve high profit margins would be impacted significantly (and negatively); the public in industrial countries, on the other hand, would be forced to rely upon other energy sources (e.g., solar and wind) and enact lifestyle changes. However, many of these impacts might be positive (lower incidence of illness due to pollution, preservation of water resources, etc.).

9 Thanks to an anonymous reviewer for encouraging us to elaborate on this. 


\section{The inductive risk account of epistemically detrimental dissent}

Given our discussion of inductive risk, conventional standards, and producer and public risks, we are now in a position to formulate a set of conditions that are jointly sufficient for epistemically detrimental dissent in general:

Dissent from a hypothesis $\mathrm{H}$ is epistemically detrimental if each of the following obtains:

1. The non-epistemic consequences of wrongly rejecting $\mathrm{H}$ are likely to be severe.

2. The dissenting research that constitutes the objection violates established conventional standards.

3. The dissenting research involves intolerance for producer risks at the expense of public risks.

4. Producer risks and public risks fall largely upon different parties.

We refer to this account, again, as the inductive risk account of epistemically detrimental dissent (or simply, the inductive risk account). In this section, we will provide a defense of it.

It is first important to discuss why we introduce an inductive risk account at all, given that our aim is to distinguish between epistemically beneficial and epistemically detrimental dissent. What is the connection between this account and the inhibition of knowledge production?10 It is clear how research that meets the conditions of the account could lead to bad consequences in an ethical sense, but at first glance it is much less clear how such research could lead to detrimental consequences in an epistemic sense.

To begin to explain this, consider contemporary dissent from a very different hypothesis - namely, the Einsteinian hypothesis that simultaneity is relative. Suppose furthermore that this dissent involves a violation of established conventional standards. Should we consider this dissent to be epistemically detrimental, in the sense of impeding knowledge production? We do not believe so. We should consider the dissent to be an instance of bad science (due to the violation of established conventional standards), but not of epistemically detrimental dissent, and we should not consider it to be epistemically

10 We are grateful to Torsten Wilholt for discussion on this point. 
detrimental dissent because it will have virtually no impact on scientific progress at all. Scientists who continue to defend the relativity of simultaneity in the face of this dissent will encounter a very different atmosphere than that of current climate science. They will not be forced to respond over and over again to the same bad arguments. They will not be dragged before houses of congress or parliament and asked to justify their conclusions. They will not have their emails hacked and taken out of context, and they will not find themselves at the center of a controversy called "simultaneity-gate." The main reason why none of these unfortunate circumstances will befall the defenders of the relativity of simultaneity is that the non-epistemic consequences of wrongly rejecting (or accepting) this hypothesis are negligible, especially in comparison to hypotheses like anthropogenic climate change; in particular, there are no significant financial consequences for powerful political and/or economic stakeholders.

The implications of the inductive risk account for the inhibition of knowledge production become apparent when one notes that industry is exerting increasing influence over many aspects of scientific research. In particular, there are three types of influence that are important for the purposes of this discussion. First, in many areas of research, financial considerations directly influence the ways in which research is conducted - including the choice of research problems, the choice of methods, and the interpretation of data. An example of this would be industry-funded pharmaceutical research that is organized so as to maximize the probability of obtaining a desired result (e.g., Bekelman et al. 2003; Biddle 2007, 2013; Brown 2008; Vom Saal and Hughes 2005; Wilholt 2009). Secondly, in many areas of research, financial considerations directly influence the ways in which research is disseminated. They influence, for example, decisions about whether or not to publish a result and how research results should be marketed (e.g., Sismondo 2007, 2008). Thirdly, in many areas, financial considerations indirectly influence research by creating an atmosphere in which researchers fear to investigate particular hypotheses or draw particular conclusions. This is done by structuring incentives toward industry-friendly projects and conclusions. In these areas, researchers who perform industry-friendly research are more likely to be rewarded with funding, consultancy arrangements, speaking engagements, and the like, while researchers who perform research that is critical of industry are more likely to be subjected to various forms of intimidation (e.g., Krimsky 2003; McGarity and Wagner 2008). In what follows, we will discuss how these three types of influence apply to climate science. 
In climate science, financial interests do influence some research projects directly (e.g., Gelbspan 1997). For example, as discussed earlier, the offer of the AEI was awarded to scientists who provide results that contradict the fourth assessment report of the IPCC; given this, the offer is likely to elicit research that is skewed in order to avoid producer risks. At the same time, there is much research in climate science that is not directly affected by financial interests. There are many projects that are funded by the public and that are conducted in universities or government laboratories (such as the projects of the climate scientists discussed in Sections 3 and 4), and the vast majority of the scientists conducting these projects do not dispute that anthropogenic climate change is occurring (e.g., Oreskes 2004). Because of this, it is reasonable to think that the direct influence of financial considerations upon research in climate science is not a significant problem.

However, the direct influence of financial interests on the ways in which specific research results are disseminated is a serious problem for climate science. There is now a sophisticated, privately-funded network for disseminating results that contradict the hypothesis of anthropogenic climate change. Oreskes and Conway (2010) examine the role of the conservative Marshall Institute in promoting and disseminating contrarian claims, and Dunlap and others highlight the importance of conservative think tanks more generally in propagating climate change denialism (e.g., Dunlap and Jacques 2013; Elsasser and Dunlap 2013; Jacques et al. 2008). The strategies of dissemination developed by these foundations have been effective in identifying dissenting research, targeting prominent media outlets, and ensuring that the dissenting research is discussed positively in those outlets. This endows the dissenting research with political authority that is independent of the quality of the research.

The network for the dissemination of climate skepticism is related to the third type of influence, namely the structuring of incentives toward industry-friendly projects and conclusions. As we showed in Sections 3-4, dissent is often used to attack both mainstream climate scientists and climate science as a field, and these attacks can be severe and can place significant burdens on climate scientists. ${ }^{11}$

Thus, given this influence of industry on the organization of climate science - and especially on the networks for disseminating results in this area - dissent in climate

11 Traditionally, philosophers of science have not viewed dissemination as being epistemically significant; on this view, confirmation and testing are matters for epistemology, while dissemination is a matter for sociology. We have argued, however, that the way in which dissent is disseminated can have a significant impact upon the progress of science. 
science that satisfies the conditions specified in the inductive risk account is likely to impede the development of scientific knowledge. It is important to note that, on the view that we are defending, the inductive risk account is not necessarily related to the inhibition of knowledge production. We are not arguing that, in all possible worlds, research that meets the conditions of the inductive risk account inhibits the progress of science. It is possible, for example, to organize science and to regulate industry in such a way that dissent that meets these conditions is not widely disseminated, does not acquire political authority, and is not used to attack mainstream scientists. But this is not the way in which science and society are currently organized. Dissent that meets the conditions of the inductive risk account is, given current societal arrangements, likely to inhibit knowledge production, particularly because of the success of political, economic, and ideological interests in structuring the dissemination of research.

Given this account of epistemically detrimental dissent, what can we say about the AEI offer? On our account, there is nothing necessarily problematic about the offer. It could be, for example, that the offer will elicit research that is not skewed toward a particular distribution of inductive risks or does not violate conventional standards. But given the current organization of science and society, this is not likely. The offer only rewards research that contradicts the well-established consensus of anthropogenic climate change; hence it is likely to elicit research with skewed distributions of inductive risks. Moreover, given the prominent role that conservative think tanks currently have in promoting and disseminating dissent, and given the uses to which such dissent is often put, there is reason to worry that the offer will elicit research that is of questionable quality and that will be used to attack mainstream climate scientists. It is for this reason that the AEI offer is epistemically problematic.

\section{Conclusion}

In this paper, we have addressed the neglected but important problem of differentiating between epistemically beneficial and epistemically detrimental dissent in science. Usually, dissent in science is epistemically fruitful. Dissent can be beneficial even if it is based on low quality research, as it can provoke discussion and, thus, lead to a fuller understanding of the state of knowledge. In order for dissent to be epistemically problematic, it must not only be based on low quality research (or research that violates established conventional standards), it must also impede scientific progress. 
Unfortunately, dissent in some areas of science is increasingly doing just this; more and more, it is being used by stakeholders to undermine the authority of science in order to postpone inconvenient political action. In climate science, contrarian studies are often disseminated through networks established by conservative think tanks and then used as a basis for both personal and professional attacks on climate scientists. We have shown that there is strong empirical evidence that the attacks have an influence on the work of these scientists and hence on the progress of climate science.

On the basis of our discussion of climate science, we have proposed a set of jointly sufficient conditions for epistemically problematic dissent in general, which we have called the inductive risk account of epistemically detrimental dissent. On this account, dissent from a hypothesis $H$ is epistemically detrimental if each of the following obtain: (1) the non-epistemic consequences of wrongly rejecting $H$ are likely to be severe; (2) the dissenting research violates established conventional scientific quality standards; (3) the dissenting research involves intolerance for producer risks at the expense of public risks, and (4) producer risks and public risks fall largely upon different parties.

This account draws upon the literature on the role of values in science, which shows that value judgments are deeply embedded in scientific practice, including hypothesis appraisal. Scientists must make many decisions in the course of their research that are ineliminably influenced by non-epistemic values. In areas of research in which there are significant non-epistemic consequences of being wrong and in which the risks of false positives and false negatives fall largely upon different parties, nonepistemic interests can skew research in favor of some stakeholders over others. When some of these stakeholders have significant political and economic clout, as in the case of the fossil fuel industry and other related industries, dissenting research can be produced and disseminated in such a way as to inhibit scientific progress.

In our view, the inductive risk account is not necessarily related to the inhibition of knowledge production. We do not argue that, in all possible worlds, research that meets the conditions of the inductive risk account inhibits the progress of science. Rather, we argue that, given the ways in which societies are currently organized including politically and economically driven networks for disseminating as well as producing research - dissent that meets these conditions is likely to inhibit knowledge production. Thus, whether dissent is epistemically problematic depends not just upon characteristics of the scientific community, but of society at large. 


\section{References}

AEI. (2007). Letter to senators Sanders, Feinstein, Leahy, and Kerry by Christopher DeMuth. http://www.christopherdemuth.com/letter-to-senators-sanders-feinstein-leahyand-kerry.html. Accessed 19 April 2014.

Bekelman, J. E., Li, Y. \& Gross, C. P. (2003). Scope and impact of financial conflicts of interest in biomedical research: A systematic review. Journal of the American Medical Association 289 (4), 454-465.

Biddle, J. (2007). Lessons from the Vioxx debacle: What the privatization of science can teach us about social epistemology. Social Epistemology 21: 21-39.

Biddle, J. (2013). State of the field: Transient underdetermination and values in science. Studies in History and Philosophy of Science 44 (1), 124-133.

Biddle, J., \& Winsberg, E. (2010). Value judgements and the estimation of uncertainty in climate modeling. In P. D. Magnus \& J. Busch (Eds.), New waves in philosophy of science (pp. 172-197). Basingstoke, Hampshire: Palgrave MacMillan.

Bowen, M. (2008). Censoring science: Inside the political attack on Dr. James Hansen and the truth of global warming. New York: Dutton.

Brown, J. R. (2008). The community of science ${ }^{\circledR}$. In M. Carrier, D. A. Howard, \& J. Kourany (Eds.), The challenge of the social and the pressure of practice (pp. 189-216). Pittsburgh: University of Pittsburgh Press.

Brysse, K., Oreskes, N. O’Reilly, J., \& Oppenheimer, M. (2012). Climate change prediction: Erring on the side of least drama? Global Environmental Change 23, 327337.

Douglas, H. (2000). Inductive risk and values in science. Philosophy of Science 67 (4), 559-579. 
Dunlap, R. E. (2013). Climate change skepticism and denial: An introduction. American Behavioral Scientist 57 (6), 691-698.

Dunlap, R. E., \& Jacques, P. J. (2013). Climate change denial books and conservative think tanks: Exploring the connection. American Behavioral Scientist 57, 699-731.

Elliott, K. (2011). Is a little pollution good for you? Oxford: Oxford University Press.

Elsasser, S. W., \& Dunlap, R. E. (2013). Leading voices in the denier choir: Conservative columnists' dismissal of global warming and denigration of climate science. American Behavioral Scientist 57 (6), 754-776.

Freudenburg, W. R., \& Muselli, V. (2010). Global warming estimates, media expectations, and the asymmetry of scientific challenge. Global Environmental Change 20, 483-491.

Gelbspan, R. (1997). The heat is on. New York: Perseus Books.

IPCC (1995). Climate change 1995: A report of the Intergovernmental Panel on Climate Change. https://www.ipcc.ch/pdf/climate-changes-1995/ipcc-2nd-assessment/2ndassessment-en.pdf. Accessed 19 April 2014.

IPCC (2013). Summary for policy makers. In T. F. Stocker, D. Qin, G.-K. Plattner, M. Tignor, S. K. Allen, J. Boschung, A. Nauels, Y. Xia, V. Bex \& P. M. Midgley (Eds.), Climate change 2013: The physical science basis. Contribution of working group I to the fifth assessment report of the Intergovernmental Panel on Climate Change. Cambridge, UK, and New York, NY: Cambridge University Press.

Jacques, P. J., Dunlap, R. E., \& Freeman, M. (2008). The organization of denial: Conservative think tanks and environmental skepticism. Environmental Politics 17, 349385.

Jeffrey, R. (1956). Valuation and acceptance of scientific hypotheses. Philosophy of Science 23 (3), 237-246. 
Kitcher, P. (1993). The advancement of science. Science without legend, objectivity without illusions. New York: Oxford University Press.

Kitcher, P. (2011). Science in a democratic society. New York: Prometheus Books.

Krimsky, S. (2003). Science in the private interest: Has the lure of profits corrupted biomedical research? Lanham, MD: Rowman \& Littlefield.

Kuhn, T. S. (1962). The structure of scientific revolutions. University of Chicago Press.

Kuhn, T. S. (1977). Objectivity, value judgment, and theory choice. In The Essential Tension: Selected Studies in Scientific Tradition and Change (pp. 320-339). Chicago: University of Chicago Press.

Lahsen, M. (2008). Experiences of modernity in the greenhouse. A cultural analysis of a physicist "trio" supporting the backlash against global warming. Global Environmental Change 18, 204-219.

Lakatos, I. (1970). Falsification and the methodology of scientific research programmes. In I. Lakatos \& A. Musgrave (Eds.), Criticism and the growth of knowledge (pp. 91-196). Cambridge: Cambridge University Press.

Levi, I. (1960). Must the scientist make value judgments? The Journal of Philosophy 57 (11), 345-357.

Lewandowsky, S., Gignac, G. E., \& Oberauer, K. (2013). The role of conspiracist ideation and worldviews in predicting rejection of science. PLOS One 8 (10), e75637.

Lloyd, E. A. (2012). The role of 'complex' empiricism in the debates about satellite data and climate models. Studies in History and Philosophy of Science 43 (2), 390-401.

Longino, H. (2002). The fate of knowledge. Princeton, NJ: Princeton University Press. 
Mann, M. (2012). The hockey stick and the climate wars. Dispatches from the front lines. New York: Columbia University Press.

Mann, M. E., Bradley, R. S., \& Hughes, M. K. (1998). Global-scale temperature patterns and climate forcing over the past six centuries. Nature 392, 779-787.

Mann, M. E., Bradley, R. S., \& Hughes, M. K. (1999). Northern-hemisphere temperatures during the past millennium: Inferences, uncertainties, and limitations. Geophysical Research Letters 26, 759-762.

McGarity, T. O., \& Wagner, W. E. (2008). Bending science. Cambridge, MA: Harvard University Press.

Mclntyre, S. \& McKitrick, R. (2003). Corrections to Mann et al. [1998] proxy database and northern hemisphere average temperature series. Energy and Environment 14, $751-771$.

McIntyre, S. \& McKitrick, R. (2005). Hockey sticks, principle components, and spurious significance. Geophysical Research Letters 32, L03710.

NRC (2009). Restructuring federal climate research to meet the challenges of climate change. Washington, DC: The National Academies Press.

Oreskes, N. (2004). The scientific consensus on climate change. Science 306, 1686.

Oreskes, N., \& Conway, E. (2010). Merchants of doubt. New York: Bloomsbury Press.

Proctor, R., \& Schiebinger, L. (2008). Agnotology: The making and unmaking of ignorance. Stanford: Stanford University Press. 
Rahmstorf, S., Cazenave, A., Church, J. A., Hansen, J. E., Keeling, R. F., Parker, D. E., \& Somerville, R. C. J. (2007). Recent climate observations compared to projections. Science 316, 709.

Regalado, A. (2005). In climate debate, the 'hockey stick' leads to a face-off. Wall Street Journal (February 14). http://online.wsj.com/news/articles/SB110834031507653590. Accessed 15 May 2014.

Rudner, R. (1953). The scientist qua scientist makes value judgments. Philosophy of Science $20(1), 1-6$.

Rutherford, S., Mann, M. E., Osborn, T. J., Bradley, R. S., Briffa, K. R., Hughes, M. K., \& Jones, P. D. (2005). Proxy-based northern hemisphere surface temperature reconstructions: Sensitivity to method, predictor network, target season, and target domain. Journal of Climate 18, 2308-2329.

Schneider, S. (2009). Science as a contact sport: Inside the battle to save Earth's climate. Washington, DC: National Geographic Society.

Sills, J. (2010). Climate change and the integrity of science. Science 328, 689-691.

Sismondo, S. (2007). Ghost management: How much of the medical literature is shaped behind the scenes by the pharmaceutical industry? PLoS Medicine 4 (9), e286.

UNEP (2009). Climate change science compendium 2009. http://www.unep.org/pdf/ccScienceCompendium2009/cc_ScienceCompendium2009_ full_highres_en.pdf. Accessed 19 April 2014. 
Vom Saal, F. S., \& Hughes, C. (2005). An extensive new literature concerning low-dose effects of bisphenol A shows the need for a new risk assessment. Environmental Health Perspectives 113 (8), 926-933.

Wahl, E. R., \& Ammann, C. M. (2007). Robustness of the Mann, Bradley, Hughes reconstruction of Northern Hemisphere surface temperatures: Examination of criticisms based on the nature and processing of proxy climate evidence. Climatic Change 85, 3369.

Wilholt, T. (2009). Bias and values in scientific research. Studies in History and Philosophy of Science 40 (1), 92-101. 